\title{
COMMENTARY
}

\section{PSA for prostate cancer detection: In serum, in urine or both?}

\author{
Armen Aprikian, MD
}

See related article on page 377

$\mathrm{S}$ ince the discovery of prostate specific antigen (PSA) and its relation to prostate cancer detection, there have been countless studies attempting to improve its accuracy. "Improve detection and avoid unnecessary biopsies" has been the objective for more than 2 decades. Surprisingly, after so many years of defining and fine-tuning its use for clinical practice, the PCPT study ${ }^{1}$ painfully showed us that prostate cancer can be found no matter what level of serum PSA.

In this issue of CUAJ Bolduc and colleagues ${ }^{2}$ report on their experience of measuring urinary PSA in the hopes of improving the accuracy of serum PSA in prostate cancer early detection. Although this is not the first time such an attempt has been made, these authors have made some unique observations. Despite the small number of cases, the authors observed that at a cutoff of $150 \mathrm{ng} / \mathrm{mL}$ for urinary PSA an impressive sensitivity of $92.5 \%$ was achieved. Unfortunately, there was no clear relation with cancer grade, but urinary PSA appeared to be helpful in addition to serum PSA for identifying more advanced stage cancers.

Obviously, a much larger series of cases and controls is required to validate the usefulness in everyday clinical practice. For those urologists who are looking for ways to reduce unnecessary prostatic biopsies, urinary PSA may one day be added to the series of biomarkers and nomograms for such a purpose. However, for those who do not wish to miss any prostate cancers, urinary PSA will probably not be very useful. Interestingly, one can probably say the same for serum PSA. Nevertheless, if urinary PSA can indeed provide additional prognostic information over serum PSA in the low levels, then it would be most welcome.

Head, Division of Urology, McGill University, Montréal, Que.

Competing interests: None declared.

\section{References}

1. Thompson IM, Goodman PJ, Tangen $C M$, et al. The influence on finasteride on the development of prostate cancer. N Engl J Med 2003;349:215-24.

2. Bolduc S, Lacombe L, Naud A, et al. Urinary PSA: a potential useful marker when serum PSA is between $2.5 \mathrm{ng} / \mathrm{mL}$ and $10 \mathrm{ng} / \mathrm{mL}$. CUAJ 2007; 1:377-81.

Correspondence: Dr. A. Aprikian, MUHC-Montreal General Hospital, 1650 Cedar Ave., L8-309, Montréal QC H3G 1A4; armen.aprikian@muhc.mcgill.ca 